\title{
Guiding the conversation - types of regret after gender-affirming surgery and their associated etiologies
}

\author{
Sasha Karan Narayan ${ }^{1}$, Rayisa Hontscharuk², Sara Danker ${ }^{3}$, Jess Guerriero ${ }^{4}$, Angela Carter ${ }^{5}$, Gaines \\ Blasdel $^{6}$, Rachel Bluebond-Langner ${ }^{6}$, Randi Ettner ${ }^{7}$, Asa Radix ${ }^{8}$, Loren Schechter ${ }^{910,11}$, Jens Urs Berli ${ }^{12}$ \\ ${ }^{1}$ Department of Surgery, Oregon Health and Science University, Portland, OR, USA; ${ }^{2}$ Department of Plastic and Reconstructive Surgery, Rush \\ University Medical Center, Chicago, IL, USA; ${ }^{3}$ Division of Plastic Surgery, University of Miami Miller School of Medicine, Miami, FL, USA; \\ ${ }^{4}$ Transgender Health Program, Oregon Health \& Science University, Portland, OR, USA; ${ }^{5}$ Primary Care, Equi Institute, Portland, OR, USA; ${ }^{6}$ NYU \\ Langone Health, New York, NY, USA; ${ }^{7}$ University of Minnesota, Minneapolis, MN, USA; ${ }^{8}$ Callen-Lorde Community Health Center, New York, \\ NY, USA; ${ }^{9}$ The University of Illinois at Chicago, Chicago, IL, USA; ${ }^{10}$ Rush University Medical Center, Chicago, IL, USA; ${ }^{11}$ The Center for Gender \\ Confirmation Surgery, Weiss Memorial Hospital, Chicago, IL, USA; ${ }^{12}$ Division of Plastic \& Reconstructive Surgery, Oregon Health \& Science \\ University, Portland, OR, USA \\ Contributions: (I) Conception and design: S Danker, JU Berli; (II) Administrative support: SK Narayan, S Danker, JU Berli; (III) Provision of study \\ materials or patients: S Danker, JU Berli; (IV) Collection and assembly of data: SK Narayan, S Danker, JU Berli; (V) Data analysis and interpretation: \\ SK Narayan, J Guerriero, L Schechter, JU Berli, R Hontscharuk; (VI) Manuscript writing: All authors; (VII) Final approval of manuscript: All authors. \\ Correspondence to: Jens Urs Berli, MD. Division of Plastic \& Reconstructive Surgery, Oregon Health \& Science University, 3181 SW Sam Jackson \\ Road Park, MAC 3168, Portland, OR 97239-3079, USA. Email: berli@ohsu.edu.
}

Background: A rare, but consequential, risk of gender affirming surgery (GAS) is post-operative regret resulting in a request for surgical reversal. Studies on regret and surgical reversal are scarce, and there is no standard terminology regarding either etiology and/or classification of the various forms of regret. This study includes a survey of surgeons' experience with patient regret and requests for reversal surgery, a literature review on the topic of regret, and expert, consensus opinion designed to establish a classification system for the etiology and types of regret experienced by some patients.

Methods: This anonymous survey was sent to the 154 surgeons who registered for the 2016 World Professional Association for Transgender Health (WPATH) conference and the 2017 USPATH conference. Responses were analyzed using descriptive statistics. A MeSH search of the gender-affirming outcomes literature was performed on PubMed for relevant studies pertaining to regret. Original research and review studies that were thought to discuss regret were included for full text review.

Results: The literature is inconsistent regarding etiology and classification of regret following GAS. Of the 154 surgeons queried, 30\% responded to our survey. Cumulatively, these respondents treated between 18,125 and 27,325 individuals. Fifty-seven percent of surgeons encountered at least one patient who expressed regret, with a total of 62 patients expressing regret (0.2-0.3\%). Etiologies of regret were varied and classified as either: (I) true gender-related regret (42\%), (II) social regret (37\%), and (III) medical regret (8\%). The surgeons' experience with patient regret and request for reversal was consistent with the existing literature.

Conclusions: In this study, regret following GAS was rare and was consistent with the existing literature. Regret can be classified as true gender-related regret, social regret and medical regret resulting from complications, function, pre-intervention decision making. Guidelines in transgender health should offer preventive strategies as well as treatment recommendations, should a patient experience regret. Future studies and scientific discourse are encouraged on this important topic.

Keywords: Transgender surgery; transgender regret; detransition; reversal surgery; retransition; gender-affirming surgery

^ ORCID: 0000-0003-1283-7847. 
Submitted Sep 02, 2020. Accepted for publication Feb 07, 2021.

doi: 10.21037/atm-20-6204

View this article at: http://dx.doi.org/10.21037/atm-20-6204

\section{Introduction}

Over the past several years, there has been sustained growth in institutional and social support for transgender and gender non-conforming (TGNC) care, including genderaffirming surgery (GAS) (1). The American Society of Plastic Surgeons (ASPS) estimates that in 2016, no less than 3,200 gender-affirming surgeries were performed by ASPS surgeons. This represents a $20 \%$ increase over 2015 (2) and may be partially attributable to an increase in third party coverage $(3,4)$. A rare, but consequential, risk of GAS is post-operative regret that could lead to requests for surgical reversal. As the number of patients seeking surgery increases, the absolute number of patients who experience regret is also likely to increase. While access to genderaffirming health care has expanded, these gains are under continued threat by various independent organizations, religious, and political groups that are questioning the legitimacy of this aspect of healthcare despite an evergrowing body of scientific literature supporting the medical necessity of many surgical and non-surgical affirming interventions. It is therefore not surprising that studies on regret and surgical reversal are scarce compared to studies on satisfaction and patient-reported outcomes. The transgender community rightfully fears that studies on this topic can be miscited to undermine the right to access to healthcare.

The goal of this study is to assist patients, professionals, and policy makers regarding this important, albeit rare, occurrence. We do so by addressing the following:

(I) The current literature regarding the etiology of regret following gender-affirming surgery;

(II) The experience of surgeons regarding requests for surgical reversal.

Based on these results, the authors propose a classification system for both type and etiology of regret.

It is important to acknowledge that the authors identify along the gender spectrum and are experts in the field of transgender health (mental health, primary care, and surgery). We hope to facilitate discussion regarding this multifaceted and complex topic to provide a stepping-stone for future scientific discussion and guideline development. Our ultimate goal is to reduce the possibility of regret and provide clinical support to patients suffering from the sequelae of regret. We present the following article in accordance with the SURGE reporting checklist (available at http://dx.doi.org/10.21037/atm-20-6204).

\section{Methods}

\section{Survey}

A 16-question survey (see Table S1) was developed and uploaded to the online survey platform SurveyMonkey (SurveyMonkey, Inc., San Mateo, CA, USA). This anonymous survey was e-mailed by the senior author to the 154 surgeons who registered for the 2016 World Professional Association for Transgender Health (WPATH) conference and the 2017 USPATH conference. There were no incentives offered for completing this survey. One reminder e-mail was sent after the initial invitation.

Respondents were asked to describe their practices, including: country of practice, years in practice, a range estimate of the total number of TGNC patients surgically treated, and the number of TGNC patients seen in consultation who expressed regret and a desire to reverse or remove the gendered aspects of a previous gender-affirming surgery. We limited the questions to breast and genital procedures only. Facial surgery was excluded as there are no associated WPATH criteria, so there is less standardization of patient selection for surgery. Thus, we did not feel that those patients should be pooled with those who were subject to WPATH criteria in our calculation for prevalence of regret. We did not define the term "regret" in order to capture a wide range of responses. Respondents were asked about their patients' gender-identification, the patient's surgical transition history, and the patient's reasons for requesting reversal surgery. If the respondents had experience with patients seeking reversal surgery, the number of such interventions were queried to include: the initial genderaffirming procedure and the patients' reason(s) for requesting reversal procedures. The respondents were also asked about the number of reversal procedures they had performed, and what requirements, if any, they would/did have prior to performing such procedures. Finally, respondents were asked whether they believed that the WPATH Standards of Care 8 should address this topic. 


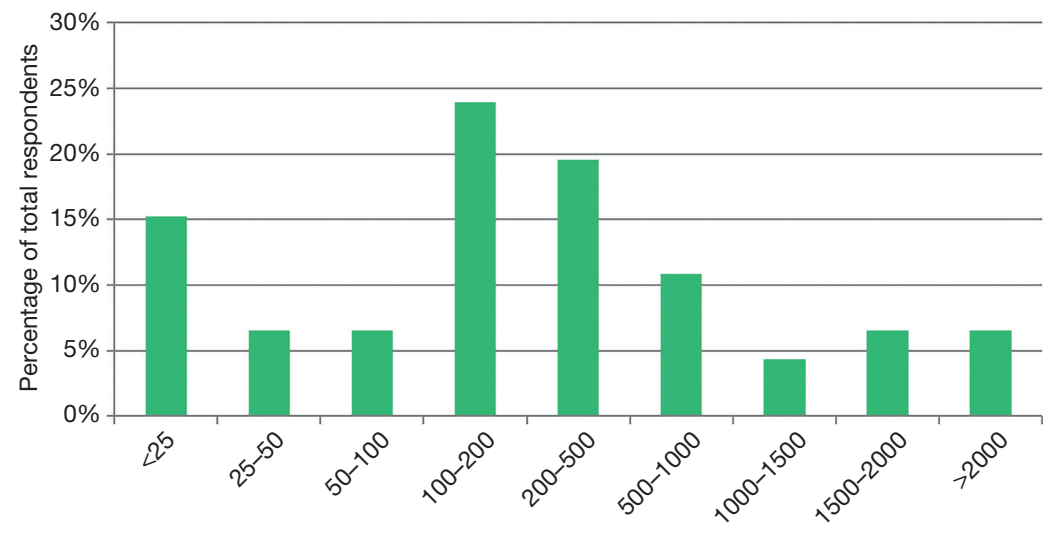

Number of transgender patients treated surgically

Figure 1 Distribution of transgender surgery experiences among respondents.

\section{Statistical analysis}

Response rate was calculated from the total number of respondents as compared to the number of unique survey invitations sent. Responses to the survey were analyzed using descriptive statistics. When survey questions offered ranges, (i.e., estimating the number of patients surgically treated), the minimum and maximum values of each of the selected answers were independently summed to report a more comprehensible view of the data. Partially completed surveys were identified individually and accounted for in analysis. Any missing or incomplete data items from the survey were excluded from the results with the denominator adjusted accordingly.

\section{Narrative literature review}

A MeSH search of the gender-affirming outcomes literature was performed on PubMed for relevant studies pertaining to regret and satisfaction. Terms included (regret) and (transgender) and (surgery) or (satisfaction) and (transgender) and (surgery). These terms included their permutations according to the PubMed search methodology. Original research and review studies whose abstracts addressed the following topics were included for full-text review: genderaffirming surgery, sex reassignment, patient satisfaction, detransition, regret. A total of 163 abstracts were reviewed and a total of 21 articles were closely read for the relevant discussion of regret and satisfaction.

\section{Ethical statement}

This study was approved by the Oregon Health \& Science
Institutional Review Board \#17450 and was conducted in accordance with the Declaration of Helsinki (as revised in 2013). Subjects were physicians and so gave consent through their participation in the survey. The patients who were captured in the study were not individually consented for this research as the IRB felt it to be unnecessary given the degree of separation of the study and lack of identifiers. None of the study outcomes affect future management of the patients' care.

\section{Results}

\section{Survey results}

Of the 154 surgeons who received the survey between December 2017 and February 2018, 46 (30\%) surgeons completed the survey. The survey, including its results, can be found in Table S1. Thirty respondents $(65 \%)$ were in practice for greater than 10 years, and most $(67 \%)$ practice in the United States, followed by Europe (22\%). The respondents treated between 18,125 and 27,325 TGNC or gender non-conforming (TGNC) patients. Most of the respondents $(72 \%)$ surgically treated over 100 TGNC patients (see Figure 1). Of the 46 respondents, $61 \%$ of respondents encountered either at least one patient with regret regarding their surgical transition or a patient who sought a reversal procedure-irrespective of whether their initial surgery was performed by the respondent or another surgeon. Twelve respondents (26\%) encountered one patient with regret, and the remaining 12 (26\%) encountered two or more patients with regret. One respondent indicated that they encountered between 10 and 


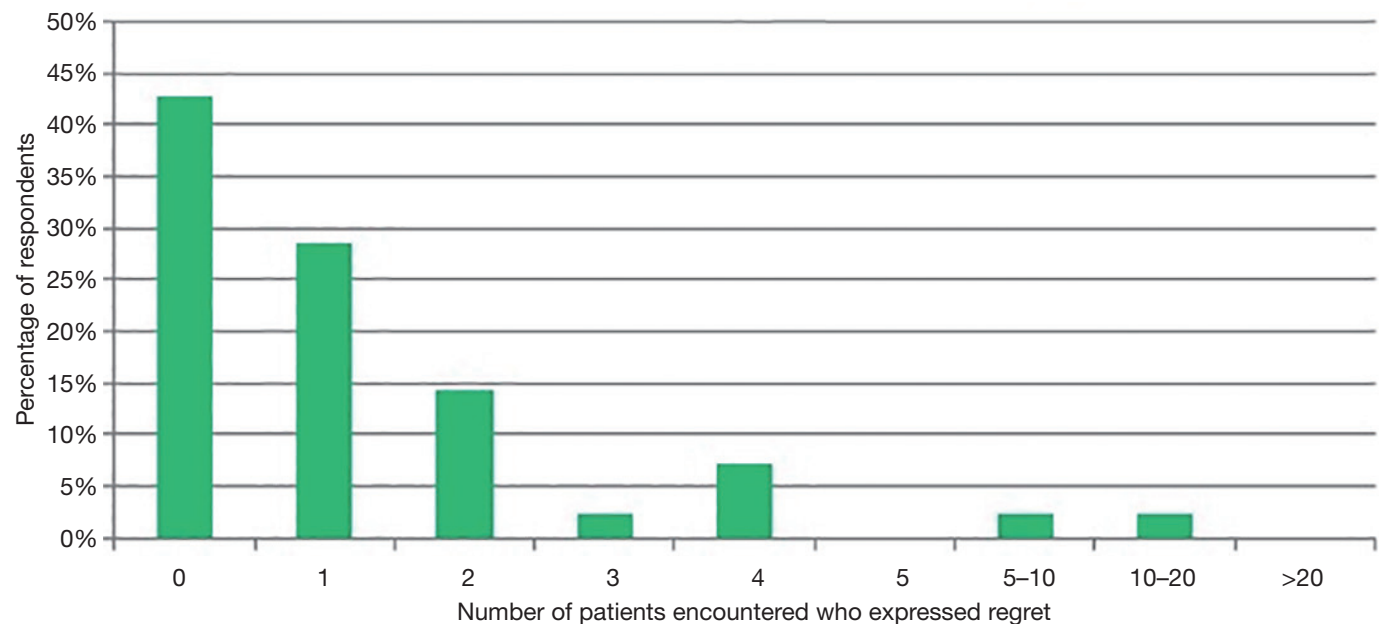

Figure 2 Number of transgender patients encountered who expressed regret.

Table 1 Regretful patients encountered and surgeries performed

\begin{tabular}{|c|c|c|}
\hline Results regarding regret and reversal & $\mathrm{N}$ & $\%$ \\
\hline Total regretful patients encountered & 62 & 100.0 \\
\hline \multicolumn{3}{|c|}{ Type of procedure patient sought to reverse } \\
\hline Chest surgery & 13 & 21.0 \\
\hline Genital surgery & 45 & 72.6 \\
\hline \multicolumn{3}{|l|}{ Reversal procedures performed } \\
\hline Reversal of mastectomy & 0 & 0 \\
\hline Reversal of breast augmentation & 6 & 9.7 \\
\hline Reversal of phalloplasty & 16 & 25.8 \\
\hline Reversal of vaginoplasty & 1 & 1.6 \\
\hline \multicolumn{3}{|c|}{ Regretful patients encountered, per surgeon respondent } \\
\hline 0 & 18 & 39.1 \\
\hline 1 & 12 & 26.1 \\
\hline 2 & 6 & 13.0 \\
\hline 3 & 1 & 2.2 \\
\hline 4 & 3 & 6.5 \\
\hline 5 & 0 & 0.00 \\
\hline $5-10$ & 1 & 2.2 \\
\hline $10-20$ & 1 & 2.2 \\
\hline$>20$ & 0 & 0.0 \\
\hline
\end{tabular}

Totals do not add to 100 due to incomplete responses.
20 patients who regretted their surgical gender transition. No respondent encountered more than 20 such patients (see Figure 2). This amounted to a total of 62 patients with regret regarding surgical transition, or a $0.2 \%$ to $0.3 \%$ rate of regret. Of these 62 patients, 13 (21\%) involved chest/breast surgery and $45(73 \%)$ involved genital surgery (see Table 1).

Of the 62 patients who sought surgical reversal procedures, at the time of their initial gender-affirming surgery, 19 patients identified as trans-men, 37 identified as trans women, and 6 identified as non-binary. The reasons for pursuing surgical reversal were provided for 46 patients (74\%) and included: change in gender identity or misdiagnosis (26 patients, $42 \%$ ), rejection or alienation from family or social support (9 patients, $15 \%$ ), and difficulty in romantic relationships (7 patients, $11 \%$ ). In some patients, surgical complications or social factors were cited as a reason for regret and request for reversal of genital surgery-no change in the patient's gender identity was elucidated (see Table 2, etiologies of regret). Of the 37 trans-women seeking reversal procedures, complaints at the time of secondary surgical consultation included: vaginal stenosis (7 patients), rectovaginal fistulae (2 patients), and chronic genital pain (3 patients). Of the 19 trans-men seeking reversal procedures, complaints at the time of secondary surgical consultation included: urethral fistulae ( 2 patients) and urethral stricture (1 patient). A total of 36 reversal procedures were reported, with supplemental 
Table 2 Etiologies of regret as seen in our survey

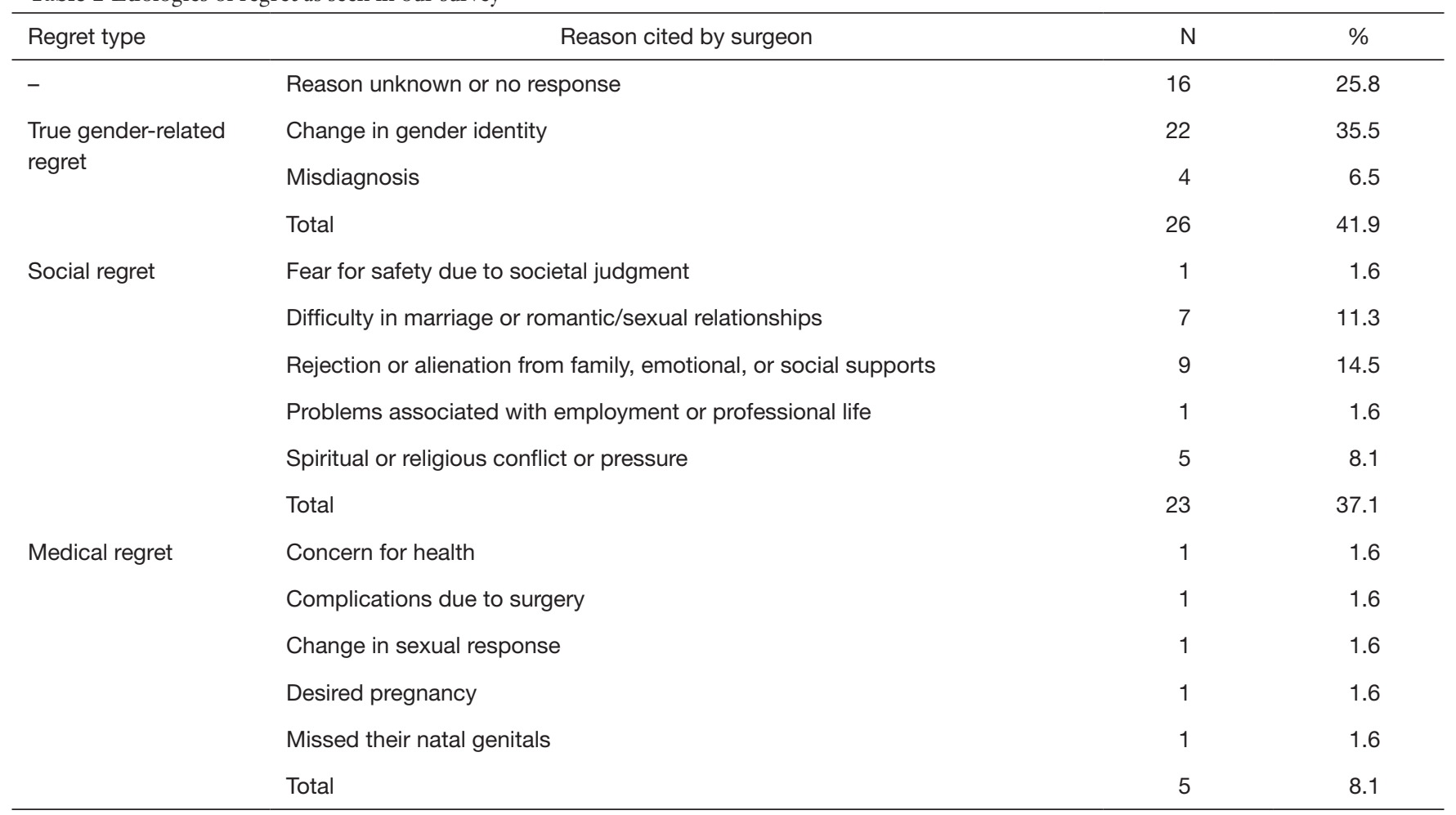

Totals exceed 100 as respondents could select multiple options.

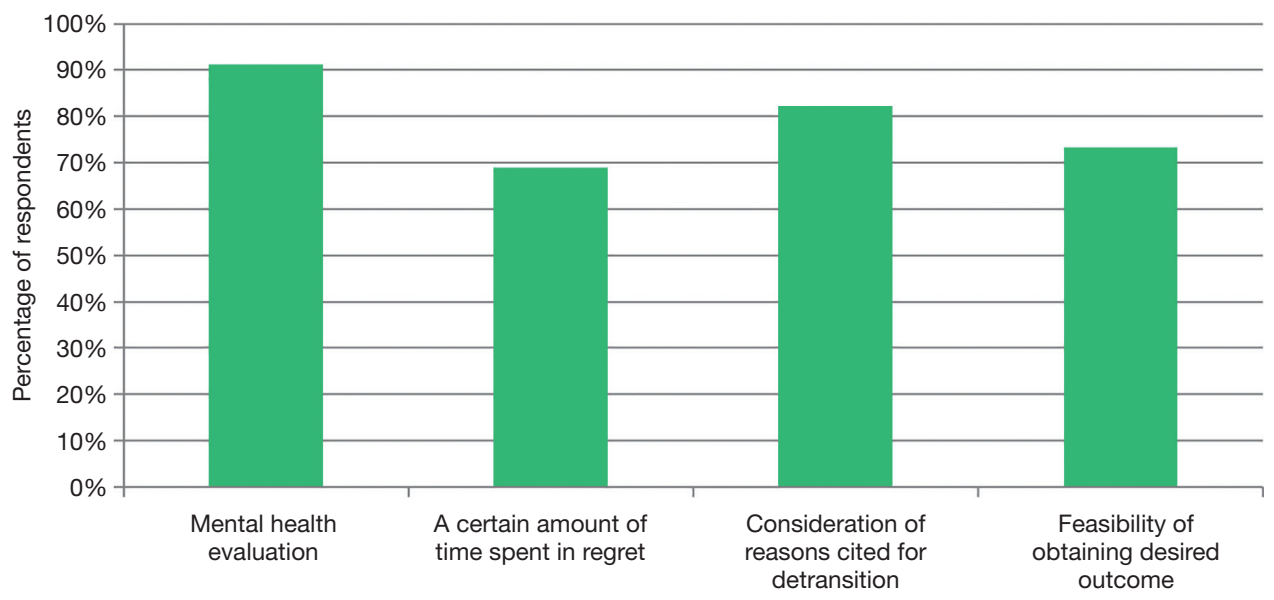

Figure 3 Respondent's requirements to proceed with surgical reversal.

qualitative descriptions provided for only 23 procedures. The distribution of the 23 reversal procedures is found in Table 1.

Most respondents (91\%) indicated that new mental health evaluations would be required prior to performing surgical reversal procedures. Eighty-eight percent of respondents indicated that WPATH SOC 8 should include a chapter on reversal procedures (see Figure 3).

\section{Literature review}

Overall, the incidence of regret following gender-affirming 
surgery has been reported to be consistently very low (5-26). Wiepjes et al. (27) reported an overall incidence of surgical regret in the literature in transgender men as $<1 \%$ and transgender women as $<2 \%$. Landen et al. comment that outcomes following gender-affirming surgery have improved due to preoperative patient assessment, more restrictive inclusion criteria, improved surgical techniques, and attention to postoperative psychosocial guidance (28). Although retrospective, the Wiepjes et al. study is the largest series to date and included 6,793 patients over 43 years. In this study, only 14 patients were classified as regretful, and only 10 of these patients pursued procedures consistent with intent to detransition. Perhaps most importantly, the Amsterdam team categorized regret into three main subtypes: "social regret, true regret, and feeling non-binary".

Many of the reviewed studies aimed to identify various variables or risk factors that may identify patients that are at risk or that may predict future postoperative regret.

Earlier studies focused on patient characteristics and identified several variables that were associated with regret in their patient populations. These variables include psychological variables $(11,22,23)$, such as previous history of depression $(15,26)$, character pathology $(26)$ or personality disorder $(5,15)$, history of psychotic disorder $(15,28)$, overactive temperament (26), negative self-image (26) or other psychopathology $(15,19,26)$, as well as various social or familial factors that include history of family trauma $(19,29)$, poor family support $(5,11,15,28)$, belonging to a non-core group $(28)$, previous marriage $(15,19)$, and biological parenthood $(15,19)$. Landen et al. identified poor family support as the most important variable predicting future postoperative regret in transgender men and women undergoing gender-affirming surgery in Sweden between 1972-1992 (28). Defined as subsequent application for reversal surgery, the authors found that $3.8 \%$ of their study population regretted their surgery. Other factors previously associated with regret include: sexual orientation $(5,7,15,19)$, impaired postoperative sexual function [most notably in transgender women; (29)], previous military service (29), a physically strenuous job (29), history of criminality (5), age at time of surgery and transition [ $>30$ year increased risk; $(5,6,11,15,19,29)]$, asexual or hyposexual status preoperatively $(15,29)$, too much or too little ambivalence regarding prospect of surgery (29), and/ or an absence of gender nonconformity in childhood (15).

Studies examining transgender women have identified postoperative sexual function to be a significant factor contributing to possible surgical regret $(15,29)$. A literature review by Hadj-Moussa et al. (11) (2018) identified poor sexual function as a factor that may contribute to postoperative regret in transgender women after vaginoplasty. Lindemalm et al. (29) (1986) previously reported a rate of $30 \%$ regret in their study examining 13 transgender women in Sweden after vaginoplasty. This rate of regret is the highest reported and appears to be an outlier. In their patient population, they found that only one third had a surgically-created vagina capable of sexual intercourse. This was consistent with patientreported poor postoperative sexual function and highlights the importance of discussing sexual function following vaginoplasty. Similarly, Lawrence et al. (15) (2003) found that occasional regret was reported in $6 \%$ of transgender women after vaginoplasty, with 8 of the 15 regretful patients identifying disappointing physical and functional outcomes after their surgery. These findings are consistent with literature reviews that have found that regret is related to unsatisfactory surgical outcomes and poor postoperative function (19,30).

Transgender men have been found to manifest more favorable psychosocial outcomes following surgery and are less likely to report post-surgical regret (26). These findings highlight the importance of surgical results, and their influence on surgical regret. Despite this difference between transgender men and women, overall regret continues to remain low.

While the rate of surgical regret is low, many patients can suffer from many forms of "minor regret" after surgery. Although this could skew the outcomes data (30), this is considered temporary and can be overcome with counseling. As such, this should not be calculated in assessments of true regret (30). Alternatively, lasting regret is attributed to gender dysphoria and is explicitly expressed through patient postoperative behaviors (30). Factors that have been found to contribute to "minor regret" after gender-affirming surgery include postsurgical factors such as pain during and after surgery, surgical complications, poor surgical results, loss of partners, loss of job, conflict with family, and disappointments that various expectations linked to surgery were not fulfilled (19). Previous reviews further underline the importance of following the contemporaneous WPATH Standards of Care. This is especially important regarding patient education pertaining to surgical expectations and outcomes $(11,26)$. Patient education programs are thought to identify those individuals who would most benefit from surgery (20). Other issues reported to decrease postoperative regret include appropriate preoperative 
diagnosis $(19,20,26)$, consistent administration of hormone therapy (15), adequate psychotherapy (15), and the extent to which a patient undergoes a preoperative "real-life test" living in their desired gender role $(15,19,20,26)$.

\section{Discussion}

As compared to the volume of literature regarding postoperative satisfaction following gender-affirming surgery, the literature on regret is still relatively small. However, the literature (and anecdotal surgeon reports) consistently shows low rates of regret. We juxtaposed these findings to the surgeons' experience with patients seeking reversal surgery or verbalizing regret. We found a rate of regret between $0.2-0.3 \%$. This is consistent with the most recent data from Wiepjes et al. who reported rates of regret of $0.3 \%$ for trans-masculine and $0.6 \%$ for trans-feminine patients (27). The question of prevalence seems relatively well-answered by the current literature.

Perhaps the most striking finding is the heterogeneity of etiologies and risk factors associated with regret. Within this context, establishing consistent definitions for both regret and its underlying etiology is essential. Furthermore, as our understanding of gender identity evolves, our definitions and understanding become more precise. We highlight the Wiepjes et al. classification as an example of how narrower definitions may preclude an understanding of evolving gender theory. This predominantly single-institution study included 6,793 individuals, and the authors classified regret into three subtypes: social regret, true regret, and feeling non-binary. They categorized patients as either trans-female or trans-male. Conversely, in the 2015 US Transgender Survey, $35 \%$ of the nearly 28,000 respondents reported a non-binary identification (31). The classification by Wiepjes et al. is important in that it recognizes that individuals may not regret "transitioning", but rather regret specific aspects of their medical treatment. More specifically, if these individuals request a reversal procedure, they are not necessarily requesting a "reversal" of their gender identity. However, the Wiepjes et al. study does not elaborate on this topic.

Case example: a trans-masculine, non-binary individual after testosterone therapy and chest masculinization regrets having secondary sex characteristics from hormonal therapy but is highly satisfied following chest masculinization. This should be considered true gender-related regret as the individual desires, at least in part, to return to the phenotype of the sex assigned at birth (e.g., hair removal). However, the etiology regarding this type of regret can be varied. For example, the etiology may include: insufficient exploration of the individual's gender identity [by the individual and/ or mental health professional (misdiagnosis)], lack of knowledge of professionals regarding surgical options for non-binary individuals, insurance carrier mandate to undergo hormonal therapy prior to chest masculinization (healthcare stigma), etc.

Based on the reviewed literature and our consensus expert opinion, we propose the following classification of regret, examples of etiology pertaining to regret (Table 3), and an overview of associated terminology regarding regret (Table 4).

Regret is a general term that describes an emotional state wherein a previous decision now feels incorrect. This can be temporary (fleeting ambivalence) or permanent. Permanent regret can be divided into three forms: true gender-related regret, social regret, and medical regret.

True gender-related regret involves a person having undergone a transition in gender whether by social, medical, or surgical means, indicating a formal change in gender identity, who then desires to return to their assigned sex at birth or a different gender identity. True genderrelated regret differs from other types of regret in that it implies a misdiagnosis or misinterpretation of gender incongruence at the time of transition. Based on the case example, true gender-related regret need not be related to all medical treatments, but instead may be focused on specific treatments for which the individual seeks reversal. True gender-related regret constituted $42 \%$ of the requests for surgical reversal in our study. Etiology may include: misdiagnosis, insufficient exploration of gender identity, or barriers to access for options to transition to non-binary gender expression.

Social regret refers to one's desire to return to their sex assigned at birth to alleviate the repercussions of transitioning on their social life. The etiologies can vary widely and include feeling unsafe in public, losing partnership, feeling unable to partake in one's community, and encountering professional barriers. An additional reason identified in this study included religious conflict, mentioned in $9 \%$ of individuals. Social regret was cited in $37.1 \%$ of the requests for surgical reversal.

Medical regret includes regret originating from a direct outcome of a surgery or an irreversible consequence thereof. This area is particularly important for the medical community as it is preventable and may increase as access to care expands. Medical regret can be further subdivided 
Table 3 Categorizing the etiology of regret. Regret is a general term that describes an emotional state wherein a previous decision now feels incorrect

\begin{tabular}{lll}
\hline Regret type & \multicolumn{1}{c}{ Definition } & \multicolumn{1}{c}{$\begin{array}{c}\text { Potential etiology } \\
\text { Percent citing this in } \\
\text { request for reversal }\end{array}$} \\
\hline $\begin{array}{l}\text { True gender- } \\
\text { related regret }\end{array}$ & $\begin{array}{l}\text { Involves a person having undergone a } \\
\text { transition in gender whether by social, } \\
\text { medical, or surgical means, indicating a } \\
\text { formal change in gender identity, who then } \\
\text { desires to return to their assigned sex at } \\
\text { birth or a different gender identity }\end{array}$ & $\begin{array}{l}\text { Misdiagnosis, insufficient exploration of } \\
\text { gender identity, barriers to access for non- } \\
\text { binary transition }\end{array}$ \\
& $\begin{array}{l}\text { Refers to one's desire to return to their } \\
\text { sex assigned at birth so as to ease the } \\
\text { repercussions of transitioning on their } \\
\text { societal life }\end{array}$ & $\begin{array}{l}\text { Feeling unsafe in public, loss of partnership, } \\
\text { religious conflict, inability to partake in } \\
\text { one's community, encountering professional } \\
\text { barriers }\end{array}$ \\
& $\begin{array}{l}\text { Includes regret originating from a direct } \\
\text { outcome of a surgery or an irreversible } \\
\text { consequence thereof }\end{array}$ & $\begin{array}{l}\text { Medical complications, dissatisfaction with } \\
\text { functional outcome, pre-operative decision } \\
\text { making (e.g., inadequate/incomplete } \\
\text { counseling, change in life goals) }\end{array}$ \\
\hline
\end{tabular}

Table 4 Definitions associated with regret

\begin{tabular}{ll}
\hline Term & \multicolumn{1}{c}{ Definitions } \\
\hline Gender fluidity & $\begin{array}{l}\text { An inclusive term describing gender along a spectrum rather than a binary construct. A gender fluid individual may } \\
\text { identify differently at various time points in their lives }\end{array}$ \\
$\begin{array}{l}\text { Continued } \\
\text { transition }\end{array}$ & $\begin{array}{l}\text { Treatments following initial gender-affirming procedure(s) that may relate to an evolving gender identity or request } \\
\text { further surgical consolidation of their identity. Continued transition need not be accompanied by regret for previous } \\
\text { transition }\end{array}$ \\
Detransition & $\begin{array}{l}\text { A change in gender role and/or the cessation of medical transition. This term should only be utilized for those who } \\
\text { self-identify with this experience, rather than to describe the process of surgical reversal }\end{array}$ \\
Retransition & $\begin{array}{l}\text { A phenomenon where a patient, following surgical reversal procedures, later feels that this reversal was wrong and } \\
\text { seeks to re-affirm their previously expressed gender identity }\end{array}$ \\
Fleeting & $\begin{array}{l}\text { A short term or temporary regret, often related to societal stigma or medical complications in the post-operative } \\
\text { period }\end{array}$
\end{tabular}

into regret secondary to medical complications, long-term functional outcomes (i.e., sexual), and preoperative decisionmaking.

Medical regret due to inadequate preoperative decisionmaking is directly related to a medical intervention, but it is not due to a change in gender identity, medical complication, functional outcome, or social stigma. Examples include choosing a simple-release metoidioplasty rather than a phalloplasty or regretting gonadal sterilization later in life (32). In these situations, individuals may not have appreciated the long-term implications at the time they underwent the procedure, may have received incomplete or inaccurate counseling, may have had a change in life goals, or may have not had access to technologies that are currently available. This form of regret may be mitigated by employing a multidisciplinary approach which includes discussions beyond surgical risks (i.e., fertility preservation, sexuality, etc.) $(33,34)$. Medical regret was cited in $8 \%$ of requests for reversal, however $24 \%$ of patients were separately noted to have experienced post-operative complications.

\section{Associated definitions}

Gender fluidity is an inclusive term describing gender along a spectrum rather than a binary construct. When 
applied to identity, gender fluidity, sometimes called "genderqueer" $(35,36)$ describes an individual who remains flexible regarding their identity and may identify differently at different times in their lives. Surgeons should work collaboratively with their mental health colleagues to help the patient understand the impact of surgery and how surgery may influence/affect future life goals. Nonidentified gender fluidity can be one etiology for true gender-related regret.

Continued transition medically recognizes the concept of gender fluidity and the gender spectrum. This patient seeks additional medical treatment following their initial genderaffirming procedure(s) and may express an evolving gender identity or request further surgical consolidation of their identity. The patient need not express regret over their initial transition. An example is a patient assigned maleat-birth who takes feminizing hormones and undergoes breast augmentation. Subsequently, the patient returns to the surgeon indicating they identify as non-binary and requests implant removal. With decreased stigmatization of non-binary gender identity and ability to access non-binary affirming surgical options, this type of regret may be less common in the future.

Detransition refers to a change in gender role and/or the cessation of medical transition (e.g., hormonal treatment). This term has been used controversially and disparagingly with regards to surgical transition and fails to honor the spectrum of reasons why patients may undergo reversal surgery. However, some patients utilize this term to selfidentify and to describe their experiences. This term should not be used to describe the process of surgical reversal.

Retransition is a phenomenon where a patient, following surgical reversal procedures, later feels that this reversal was wrong and seeks to re-affirm their previously expressed gender identity. A reason for retransition may include a change in societal structure that has provided a safer environment for transition. The need to distinguish continued transition from retransition results from a clash between increasing societal perception of a gender spectrum and the Western culture's binary gender construct (35).

Fleeting ambivalence (considered short-term regret) over one's transition is common, especially if the patient experiences initial surgical complications or loss of their support communities. The normal grief experienced as a result of trauma should not be pathologized, and the patient should be encouraged to trust in their long-standing gender identification. Some patients may desire a change in gender identify as a result of feeling unsafe due to severe social stigma. Knowing this, healthcare teams should counsel patients regarding the implications of transitioning within a given societal structure prior to surgery. This may include discussions regarding the effect of transitioning on relationships, careers, personal safety in public, sexuality, etc. These discussions are often facilitated by the patient's mental health professional and/or primary care provider.

\section{Special considerations}

We recognize that regret and surgical reversal are complex, multifaceted phenomena without an easy treatment path. While both regret and requests for surgical reversal are rare, the need for guideline development is critical in providing high-quality care for this patient population, regardless of prevalence.

A concern expressed by both providers and patients is that discussions regarding regret and surgical reversal may be used to restrict access to affirming care. The authors believe that research including feelings of grief and regret will not only help individuals who experience severe forms of regret but will also help to refine surgical indications and procedures to minimize this already rare occurrence. Finally, and perhaps most importantly, failure to study regret and surgical reversal procedures will allow these topics to be left up to interpretation and may not reflect the actual experience of patients.

\section{Limitations}

The literature review was not performed systematically and as such is subject to selection bias. Our survey involved a survey of gender surgeons but did not include other medical or mental health professionals who may evaluate patients requesting surgical reversal. In addition, the study findings are limited by its design. Because survey studies are prone to recall bias, response bias, and selection bias, they are not well-suited for calculating the prevalence of a particular condition. For example, $89 \%$ of the respondents practice in the United States and Europe. This leaves significant areas of the world underrepresented and so does not represent the experiences or desires of all international surgeons. Furthermore, the survey was distributed in English only, as it was circulated to surgeons who attended conferences in the United States. Most notably, patients may have sought consultation from multiple surgeons resulting in an overestimation of the prevalence of regret. Conversely, patients seeking surgical reversal may not have had access 
to additional surgical care, causing an underestimate in the prevalence of regret. While our study findings are strengthened by external validation from other studies, the true prevalence of regret remains an estimate.

\section{Conclusions}

Regret after gender-affirming surgery was found to be rare, both in the literature as well as in our survey of surgeons' experiences with this topic. Regret can be classified as true gender-related regret, social regret and medical regret from complications, function, pre-intervention decision making. Guidelines in transgender health should include both preventive strategies as well as treatment guidelines if regret occurs. Future studies and scientific discourse are encouraged on this important topic.

\section{Acknowledgments}

The authors acknowledge the many surgeons who were surveyed in this work, and the community members who thusly contributed to the survey results.

This research was orally presented by Dr. Sasha Narayan at the Philadelphia Trans Wellness Conference (PTWC) August 2018 in Philadelphia, PA and at the World Professional Association for Transgender Health (WPATH) International Conference, November 2018 in Buenos Aires, Argentina. This research was orally presented by Dr. Sara Danker at Plastic Surgery, The Meeting (PSTM), October 2018 in Chicago, IL.

Funding: None.

\section{Footnote}

Provenance and Peer Review: This article was commissioned by the Guest Editors (Drs. Oscar J. Manrique, John A Persing, and Xiaona Lu) for the series "Transgender Surgery" published in Annals of Translational Medicine. The article has undergone external peer review.

Reporting Checklist: The authors have completed the SURGE reporting checklist. Available at http://dx.doi. org/10.21037/atm-20-6204

Data Sharing Statement: Available at http://dx.doi. org/10.21037/atm-20-6204
Conflicts of Interest: All authors have completed the ICMJE uniform disclosure form (available at http://dx.doi. org/10.21037/atm-20-6204). The series "Transgender Surgery" was commissioned by the editorial office without any funding or sponsorship. Dr. RBL reports that he serves on the standards of care committee of WPATH. No financial reward. Dr. AR reports that he serves as board member for World Professional Association for Transgender Health. This is an uncompensated position. Dr. LS reports other from Elsevier Publishing, other from Springer Publishing, outside the submitted work; and he serves on the board of WPATH (world professional association for transgender health), this is an unpaid position. Dr. JUB reports that he serves on the standards of care committee of the World professional association of transgender health. No financial reward associated with this. The authors have no other conflicts of interest to declare.

Ethical Statement: The authors are accountable for all aspects of the work in ensuring that questions related to the accuracy or integrity of any part of the work are appropriately investigated and resolved. This study was approved by the Oregon Health \& Science Institutional Review Board \#17450. The study was conducted in accordance with the Declaration of Helsinki (as revised in 2013). Subjects were physicians and so gave consent through their participation in the survey. The patients who were captured in the study were not individually consented for this research as the IRB felt it to be unnecessary given the degree of separation of the study and lack of identifiers. None of the study outcomes affect future management of the patients' care.

Open Access Statement: This is an Open Access article distributed in accordance with the Creative Commons Attribution-NonCommercial-NoDerivs 4.0 International License (CC BY-NC-ND 4.0), which permits the noncommercial replication and distribution of the article with the strict proviso that no changes or edits are made and the original work is properly cited (including links to both the formal publication through the relevant DOI and the license). See: https://creativecommons.org/licenses/by-nc-nd/4.0/.

\section{References}

1. Lane M, Ives GC, Sluiter EC, et al. Trends in Gender- 
affirming Surgery in Insured Patients in the United States. Plast Reconstr Surg Glob Open 2018;6:e1738.

2. Ross A. Gender Confirmation Surgeries Rise $20 \%$ in First Ever Report: American Society of Plastic Surgeons. American Society of Plastic Surgeons, Press Releases, 2017.

3. Padula WV, Baker K. Coverage for gender-affirming care: Making health insurance work for transgender Americans. LGBT Health 2017;4:244-7.

4. Canner JK, Harfouch O, Kodadek LM, et al. Temporal Trends in Gender-Affirming Surgery Among Transgender Patients in the United States. JAMA Surg 2018;153:609-16.

5. Walinder J, Lundstrom B, Thuwe I. Prognostic Factors in the Assessment of Male Transsexuals for Sex Reassignment. Brit J Psychiat 1978;132:16-20.

6. Eldh J, Berg A, Gustafsson M. Long-term follow up after sex reassignment surgery. Scand J Plast Reconstr Surg Hand Surg 1997;31:39-45.

7. Blanchard R, Steiner BW, Clemmensen LH, et al. Prediction of regrets in postoperative transsexuals. Can J Psychiatry 1989;34:43-5.

8. Blank RJ. The partial transsexual. Am J Psychother 1981;35:107-12.

9. Edgerton MT Jr, Langman MW, Schmidt JS, et al. Psychological considerations of gender reassignment surgery. Clin Plast Surg 1982;9:355-66.

10. Lothstein LM. The postsurgical transsexual: empirical and theoretical considerations. Arch Sex Behav 1980;9:547-64.

11. Hadj-Moussa M, Ohl DA, Kuzon WM Jr. Evaluation and Treatment of Gender Dysphoria to Prepare for Gender Confirmation Surgery. Sex Med Rev 2018;6:607-17.

12. Horbach SE, Bouman MB, Smit JM, et al. Outcome of Vaginoplasty in Male-to-Female Transgenders: A Systematic Review of Surgical Techniques. J Sex Med 2015;12:1499-512.

13. Kuiper B, Cohen-Kettenis P. Sex reassignment surgery: a study of 141 Dutch transsexuals. Arch Sex Behav 1988;17:439-57.

14. Landen M, Walinder J, Lundstrom B. Prevalence, incidence and sex ratio of transsexualism. Acta Psychiatr Scand 1996;93:221-3.

15. Lawrence AA. Factors Associated with Satisfaction or Regret Following male-to-Female Sex Reassignment Surgery. Arch Sex Behav 2003;32:299-315.

16. Meyer JK, Reter DJ. Sex reassignment. Follow-up. Arch Gen Psychiatry 1979;36:1010-5.

17. Nelson L, Whallett EJ, McGregor JC. Transgender patient satisfaction following reduction mammaplasty. J
Plast Reconstr Aesthet Surg 2009;62:331-4.

18. Papadopulos NA, Lelle JD, Zavlin D, et al. Quality of Life and Patient Satisfaction Following Male-to-Female Sex Reassignment Surgery. J Sex Med 2017;14:721-30.

19. Pfafflin F. Regrets After Sex Reassignment Surgery. Journal of Psychology \& Human Sexuality 1993;5:69-85.

20. Pfäfflin F, Junge A. Geschlechtsumwandlung. Abhandlungen zur Transsexualität. Schtattauer, 1992.

21. Ross MW, Need JA. Effects of adequacy of gender reassignment surgery on psychological adjustment: a follow-up of fourteen male-to-female patients. Arch Sex Behav 1989;18:145-53.

22. Sorensen T. A follow-up study of operated transsexual females. Acta Psychiatr Scand 1981;64:50-64.

23. Sorensen T. A follow-up study of operated transsexual males. Acta Psychiatr Scand 1981;63:486-503.

24. Zavlin D, Schaff J, Lelle JD, et al. Male-to-Female Sex Reassignment Surgery using the Combined Vaginoplasty Technique: Satisfaction of Transgender Patients with Aesthetic, Functional, and Sexual Outcomes. Aesthetic Plast Surg 2018;42:178-87.

25. Poudrier G, Nolan IT, Cook TE, et al. Assessing Quality of Life and Patient-Reported Satisfaction with Masculinizing Top Surgery: A Mixed-Methods Descriptive Survey Study. Plast Reconstr Surg 2019;143:272-9.

26. Carroll RA. Outcomes of Treatment for Gender Dysphoria. Journal of Sex Education and Therapy 1999;24:128-36.

27. Wiepjes CM, Nota NM, de Blok CJM, et al. The Amsterdam Cohort of Gender Dysphoria Study (19722015): Trends in Prevalence, Treatment, and Regrets. J Sex Med 2018;15:582-90.

28. Landen M, Walinder J, Hambert G, et al. Factors predictive of regret in sex reassignment. Acta Psychiatr Scand 1998;97:284-9.

29. Lindemalm G, Korlin D, Uddenberg N. Longterm follow-up of "sex change" in 13 male-to-female transsexuals. Arch Sex Behav 1986;15:187-210.

30. Pfäfflin F, Junge A. Sex Reassignment. Thirty Years of International Follow-up Studies After Sex Reassignment Surgery: A Comprehensive Review, 1961-1991. Symposion Publishing in the Book Section of The International Journal of Transgenderism, 1998.

31. James SE, Herman JL, Rankin S, et al. The Report of the 2015 US Transgender Survey. Washington, DC: National Center for Transgender Equality, 2016.

32. Hage JJ, van Turnhout AA. Long-term outcome of metoidioplasty in 70 female-to-male transsexuals. Ann 
Plast Surg 2006;57:312-6.

33. Schechter LS, D'Arpa S, Cohen MN, et al. Gender Confirmation Surgery: Guiding Principles. J Sex Med 2017;14:852-6.

34. Deutsch MB. Gender-affirming Surgeries in the Era of Insurance Coverage: Developing a Framework for Psychosocial Support and Care Navigation in the Perioperative Period. J Health Care Poor Underserved
2016;27:386-91.

35. Baum J, Brill S, J B, et al. Supporting and caring for our gender expansive youth. Human Rights Campaign Foundation and Gender, 2013.

36. James SE, Herman J. The Report of the 2015 US Transgender Survey: Executive Summary. National Center for Transgender Equality, 2017.
Cite this article as: Narayan SK, Hontscharuk R, Danker S, Guerriero J, Carter A, Blasdel G, Bluebond-Langner R, Ettner R, Radix A, Schechter L, Berli JU. Guiding the conversationtypes of regret after gender-affirming surgery and their associated etiologies. Ann Transl Med 2021;9(7):605. doi: 10.21037/atm-20-6204 


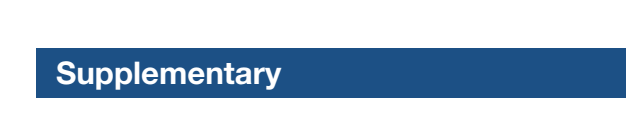

Table S1 Results of the survey study of international gender surgeons
Questions

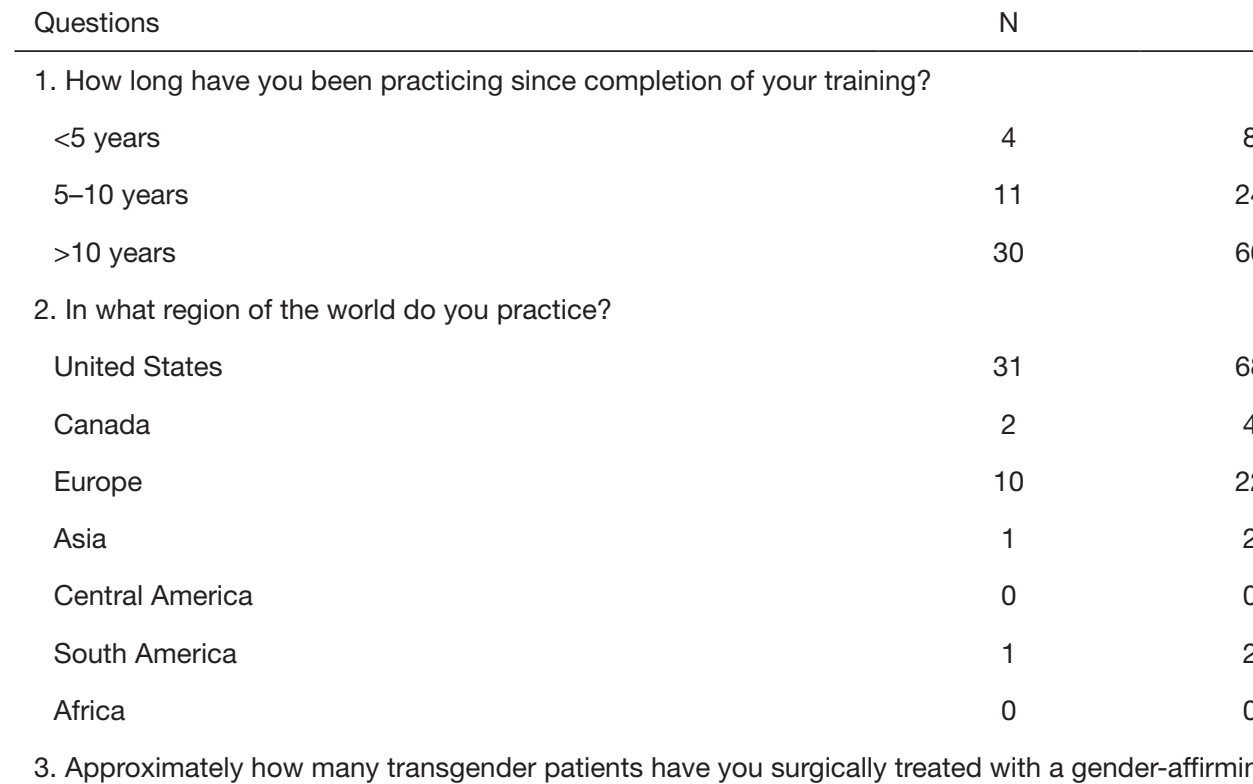

50-100

${ }^{100-200}$

$500-1,000$

$1,500-2,000$

Greater than 2,000

Yes
No

I do not perform genital surgen

5. Do you require one mental heath evaluation prior to chestbreast surgent?

Yes
No

Ido not perform chestbreast surgery

10-20

$>20$

and non-bina

Trans-male

Non-binary/ther

Then how many have there been in Chest surgery
Bottom surgen

132 category of surgery be

I. In trans-emmale patients who sought detranstion, did they experience any major complications with

inheir initial gender affiriming procedures (excluding facial feminization)? If yes, pleaese specifity what the

Vaginal It stenosis
Recto-vaginal fis

Pain

10. In trans-male patients who sought detransition, did they experience any major complications with
their initital gender affirining prococoures

Flap faliure

Frethral istula

Urethral fistula
Urethral stricture

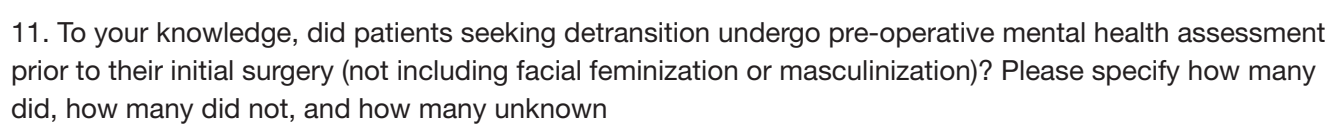

$\begin{array}{llll}\text { Number of patients who did have pre-operative mental heath } & 56 & 78.87 \\ \text { assessmment }\end{array}$

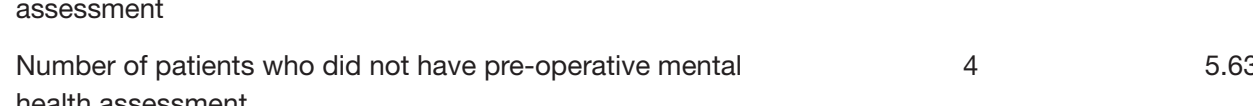

Number o f patients whose pre-operative mental heath
assessmenth

12. If y vou have experienced patients with regret, how many have you performed a detranstitining procedur

Greater than 10

政

Reversal of mastectomy

Reversal of freast augmen
Reversal o o phalloplasty

Reversal of vaginoplas

Total

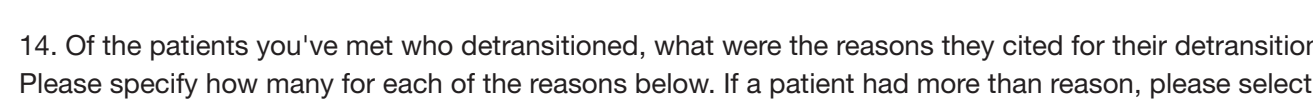

Change in gender identity

Fear for safety due to societal judgment

Fear for safety due to
Concern for heath

Problems associated with employment or profoessional inte

Dificiculty in marriage or romantic/sexual reationships

Rejection or alienation from family, emotional, or social supports

Spiritual or religious conflict or pressure

Other (please specity)
Complications due to stant

Change in sexual response

Misciagnosis

Desired pregnancy

Unknow

15. What are, or what would be,
Mental health evaluation

A certain amount of time spent in regret

Fessibity of obtaining desied out tom

Other (please specify)

Three letters of recommendation

A specialized therapist
Expectation of outcome

Total number of resspondents for this guestion 